People's Republic of China Legal Update: Supreme People's Court's Guiding Opinion on Refund Requests Relating to Unauthorised Online Video Gaming Transactions Paid for by Minors (Published 15 May 2020)

\author{
Leon Y. Xiao [0000-0003-0709-0777]* \\ $<\underline{\text { leon.xiao.y@gmail.com> }}$ \\ *: Durham Law School, Durham University, Palatine Centre, Stockton Rd, Durham, \\ United Kingdom DH1 3LE
}

Content Type: International Gaming Industry Update

Running Head: Xiao: People's Republic of China Legal Update

Word count: 1977

Conflict of Interest Declaration: None

8 June 2020 


\section{People's Republic of China Legal Update: Supreme People's Court's Guiding Opinion on Refund Requests Relating to Unauthorised Online Video Gaming Transactions Paid for by Minors (Published 15 May 2020)}

The Supreme People's Court (SPC) of the People's Republic of China (PRC) promulgated its Guiding Opinion on Several Issues Concerning the Lawful and Proper Handling of Civil Cases Involving the Novel Coronavirus Pneumonia (COVID-19) Epidemic No. 2 (hereinafter, the 'Guiding Opinion') on 15 May 2020. Paragraph 9 of the Guiding Opinion declares that: 'If a person with "limited capacity for civil conduct," without the consent of their guardian, engages with paid online video games [e.g., purchases a video game software or makes in-game purchases through microtransactions], or "donates" to content creators or makes other similar payments on livestreaming platforms, to such a sum which is "incompatible with their age and intellectual abilities," the courts shall support claims from their guardians demanding refund from the internet service providers [e.g., the game company or the livestreaming platform] for such payments. ${ }^{2}$

\section{Limited Capacity for Civil Conduct}

People's Daily Online, the online presence of the official newspaper of the Central Committee of the Communist Party of China, has reported and quoted the SPC as having made two clarifications to this Paragraph's guidance. ${ }^{3}$ The first being that the persons who have "limited capacity for civil conduct" that the Paragraph refers to and intends to protect are, in most cases, minors under the age of eighteen ${ }^{4}$

\footnotetext{
${ }^{1}$ 中华人民共和国最高人民法院 [Supreme People's Court of the People's Republic of China], 最高人民 法院关于依法妥善审理涉新冠肺炎疫情民事案件若干问题的指导意见 (二) [Guiding Opinion on Several Issues Concerning the Lawful and Proper Handling of Civil Cases Involving the Novel Coronavirus Pneumonia (COVID-19) Epidemic No. 2] 法发 (2020) 17 号 (2020), http:/ / www.court.gov.cn/zixun-xiangqing230181.html (last visited May 23, 2020)

[https: / / web.archive.org/web/20200523123626/http:/ / www.court.gov.cn/zixun-xiangqing230181.html].

${ }^{2}$ Original text in Simplified Chinese: ‘限制民事行为能力人未经其监护人同意, 参与网络付费游戏或者 网络直播平台“打赏”等方式支出与其年龄、智力不相适应的款项, 监护人请求网络服务提供者返还该款 项的，人民法院应予支持。

3 薄晨棣 [Chendi Bao] and 薛婷婷 [Tingting Xue], 最高法: 未成年参与网络直播“打赏”法院应支持返 还 [Supreme Court: Courts should support refund when minors donate to livestreams], 人民网 [PEOPLE'S DAILY ONLINE] , http:/ / legal.people.com.cn/GB/n1/2020/0519/c42510-31715319.html (last visited May 23, 2020)

[https: / / web.archive.org/web/20200523212512/http:/ / legal.people.com.cn/GB/n1/2020/0519/ c42 510-31715319.html].

${ }^{4}$ General Provisions of the Civil Law of the People's Republic of China (adopted 28 May 2020 at the Third Session of the Thirteenth National People's Congress of the People's Republic of China, effective 1 January 2021), arts. 18-19.
} 
(although the Paragraph plainly also applies to protect adults with reduced mental capacity $^{5}$ ). The SPC further argues using argumentum a fortiori, specifically argumentum a maiore ad minus, given that refund requests will be supported by the courts on a discretionary basis for payments made by persons with limited capacity for civil conduct, refund requests must be supported by the courts in all cases for payments made by persons with no capacity for civil conduct (such as minors under eight $\left.{ }^{6}\right)$, despite the Guiding Opinion not explicitly stating this.

\section{An 'Incompatible' Sum}

The SPC's second clarification relates to the amount that would constitute 'such a sum which is "incompatible with [the payer's] age and intellectual abilities."' The SPC's guidance is that there is no 'one-size-fits-all' solution to this question, and the judges must consider the facts of each case, including "the "genre" of the video game that the minor was playing; the home and family environment within which the minor developed and is developing; and the economic circumstances of the minor's family,' in order to make a holistic determination as to what sum is incompatible with any particular minor's age and intellectual abilities. ${ }^{7}$

It is unknown what the SPC means by game 'genre.' It is not justifiable for the Court to make a value judgement and argue that, for example, a child should be allowed to spend more money on a first-person shooter game than on a tilematching puzzle game. Doing so would be unfairly discriminating against certain game companies.

\section{Maximum Spending Limits}

The SPC's Guiding Opinion follows the National Press and Publication Administration (NPPA)'s recent imposition of obligations on video gaming service providers to enforce maximum spending limits against minors in November 2019 to prevent and combat 'online gaming addiction:'

\footnotetext{
${ }^{5} I d$. at art. 21.

${ }^{6}$ Id. at art. 20 .

7 薄 [Bao] and 薛 [Xue], supra note 3.

8 国家新闻出版署 [National Press and Publication Administration], 关于防止末成年人沉迷网络游戏的 通知 [Notice on the Prevention of Online Gaming Addiction in Juveniles] (2019), http: / / www.sapprft.gov.cn/ sapprft/ contents / 6588/407807.shtml (last visited Nov 20, 2019) [https: / / web.archive.org/web/20200529154145/http: / / www.sapprft.gov.cn/ sapprft/ contents / 6588 / 407807.shtml]. For translation and commentary, see Leon Y. Xiao, People's Republic of China Legal
} 
1. For juvenile users age 8 and under, online gaming service providers are not allowed to provide any paid services.

2. For juvenile users between the ages of 8 and 16, each individual transaction for in-game monetization must not exceed $¥ 50$ Renminbi (US\$7.11; £5.50), whilst total monthly spending must not exceed $¥ 200$ Renminbi (US \$28.43; $£ 22.02)$.

3. For juvenile users between the ages of 16 and 18, each individual transaction for in-game monetization must not exceed $¥ 100$ Renminbi (US\$14.21; £11.01), whilst total monthly spending must not exceed $¥ 400$ Renminbi (US\$56.85; £44.03). ${ }^{9}$

The NPPA's enumerated maximum spending limits for each age group will likely be persuasive for the courts in determining whether or not an amount of spending is incompatible with the minor's age and intellectual abilities. Any amount over the applicable limit for any particular minor's age group will likely be determined to be incompatible. Given that the NPPA prohibits video gaming service providers from providing paid services to minors under eight, the SPC's first clarification to its Guiding Opinion, that refund will be supported in all cases if the purchase was made by a minor under eight, is logical and unsurprising.

\section{Unstated Record-Keeping Obligations}

Given that game companies may now potentially be ordered by the courts to refund payments paid for by minors without parental consent in accordance with the Guiding Opinion, the companies would now be required to record and store transaction and payment details until the limitation period for potential civil claims relating to such payments expires, which would generally be three years after payment was first made, unless otherwise provided for by law. ${ }^{10}$ The existing legal obligation on online video gaming service providers to store payment and transaction details for at least 180 days, as published by the Ministry of Culture in

Update: The Notice on the Prevention of Online Gaming Addiction in Juveniles (Published October 25, 2019, Effective November 1, 2019), 24 GAMING LAW REV. 51-53, 52 (2020).

${ }^{9}$ Xiao, supra note 8 , at 52.

${ }^{10}$ General Provisions of the Civil Law of the People's Republic of China, supra note 4, at art. 188. 
December 2016 and effective since May 2017, has now been effectively extended to three years. ${ }^{11}$ Additionally, in relation to randomised products, such as loot boxes, the video gaming service providers' existing legal obligation to store the randomised 'pull' results for each transaction has also been effectively extended from 90 days to three years. ${ }^{12}$

\section{Commentary: Practicality of Refunding and Reversing Transactions: Impossibility and Fraud}

When minors made unauthorised purchases in video games in the past (and this continues to be the case in other countries), parents had to seek refunds directly from game companies or indirectly from platform providers, such as Google and Apple, through non-transparent, unreliable and highly discretionary refund request systems. ${ }^{13}$ For example, Supercell, an internationally commercially successful Finnish game company, states on its Parent's Guide, in response to the question: 'My child accidentally made an in-app purchase. Can I get a refund?,' that 'As with most downloadable software products, items bought in our games (in-app purchases) are non-refundable. In rare cases, exceptions can be applied. ${ }^{\prime 14}$ Tencent, the largest video game company in the world, has refused to reveal the evidential basis its refund approval system relies on to determine whether or not a transaction was in fact made by a minor without parental authorisation. ${ }^{15}$ Worse still, not all companies proactively combat unauthorised purchases by children using their parents' financial information: internal documents at Facebook have revealed that, as a platform provider, it actually encouraged game companies not to prevent these

\footnotetext{
11 文化部 [Ministry of Culture] (PRC)，文化部关于规范网络游戏运营加强事中事后监管工作的通知 [Notice of the Ministry of Culture on Regulating the Operation of Online Games and Strengthening Concurrent and Ex-Post Supervisions] 文市发 (2016) 32 号 (2016), para. 12, http:/ / www.mcprc.gov.cn/whzx/bnsjdt/whscs/201612/t20161205_464422.html (last visited Oct 5, 2018) [https: / / web.archive.org/web / 20171220060527/http: / / www.mcprc.gov.cn:80/whzx/bnsjdt/whscs /201612/t20161205_464422.html].

${ }^{12} \mathrm{Id}$. at para. 7.

${ }^{13}$ For a reported example in the UK, see Tom Phillips, Parents refused refund by Apple after son spends $£ 1700$ on free iPad game, EUROGAMER (2013), https: / / www.eurogamer.net/articles/2013-02-28parents-refused-refund-by-apple-after-son-spends-1700-on-free-ipad-game (last visited May 25, 2020) [https: / / web.archive.org/web/20200525112845/https:/ / www.eurogamer.net/articles / 2013-02-28parents-refused-refund-by-apple-after-son-spends-1700-on-free-ipad-game].

${ }_{14}$ Supercell, Parent's Guide, SUPERCELL, https:/ / supercell.com/en/parents/ (last visited May 25, 2020) [https: / / web.archive.org/web/20200525183823/https:/ / supercell.com/en/parents/].

15 若风 [Ruo Feng], 每天超20 起! 腾讯游戏：成年人借未成年人名义恶意申诉退款频发 [More than 20 instances every day! Tencent Games: adults requesting fraudulent refunds by using minors as an excuse occur frequently], 快科技 [KUAI KEJI] (2020), https: / / news.mydrivers.com/1/691/691140.htm (last visited May 25, 2020) [https: / / web.archive.org/web/20200525115003/https:/ / news.mydrivers.com/1/691/691140.htm].
} 
occurrences from happening and not to provide refund when appropriate in order to 'maximize revenue.' ${ }^{16}$

This Guiding Opinion has legal effect as it is 'formulation of the norms or opinions which are necessary for the trial work. ${ }^{17}$ It is welcomed as it promotes consumer protection by ensuring refund entitlement. ${ }^{18}$ It does not change the law, but it provides clarification as to the existing law's correct and appropriate application by the lower courts, and affirms that, under PRC law, parents will not be forced to pay unreasonable sums of unauthorised video gaming-related purchases made by their child. Indeed, game companies should now be more willing than before to approve refund requests from PRC parents to avoid unnecessary litigation in light of the Guiding Opinion. Further, PRC parents may now be more likely than parents from other countries to have their refund requests approved.

\section{Notwithstanding the foregoing, this Guiding Opinion brings practical} difficulties faced by game companies when refunding virtual items to the forefront. Consider this hypothetical example involving a game in which purchased virtual items can be transferred between players: if a child under eight purchases a virtual item and then trades it for other items with a third-party player acting in good faith, and if then the child's guardian obtains a guaranteed refund for the purchase from the game company in accordance with the Guiding Opinion, how should the game company resolve the situation that an extra virtual item which has not been paid for now exists within its designed virtual in-game economy? Had the child not transferred the item to a third-party, the company could have simply removed it from the child's account after the refund to ensure that no extra item has been created and that the in-game economy is not inflated. However, now that the refunded (and therefore illegitimate) item has been transferred to a third-party, should the company also remove it from the possession of the innocent third-party player in order to protect the in-game economy from inflation?

\footnotetext{
${ }^{16}$ Nathan Halverson, Facebook knowingly duped game-playing kids and their parents out of money, REVEAL (2019), https:/ / www.revealnews.org/ article/ facebook-knowingly-duped-game-playing-kids-andtheir-parents-out-of-money/ (last visited May 25, 2020) [https: / / web.archive.org/web/20200525184310/https: / / www.revealnews.org/article/facebookknowingly-duped-game-playing-kids-and-their-parents-out-of-money/].

17 最高人民法院关于司法解释工作的规定 [Provisions of the Supreme People's Court on the Judicial Interpretation Work] 法发 (2007) 12 号, arts. 5-6.

${ }^{18}$ See Daniel L. King \& Paul H. Delfabbro, Video Game Monetization (e.g., 'Loot Boxes'): a Blueprint for Practical Social Responsibility Measures, 17 InT. J. Ment. HeAlth AdDiction 166-179, 173-174 (2019).
} 
The game company has an interest in preserving and maintaining a viable ingame economy undiluted by illegitimate items because doing so increases consumer confidence in its product and encourages player investment of time and money into the game. Indeed, the interests of all other players of the game not to have their legitimate virtual items devalued is ensured by the appropriate removal of illegitimate items from the in-game economy. Accordingly, the argument for the game company to remove the illegitimate item and compensate the innocent thirdparty player by reversing the in-game transaction between this player and the child is substantial. However, if the illegitimate item was involved in multiple player transactions that involved many players, this reversal process places a particularly onerous operating burden on the game company to identify and track each transaction. Further, if players performed services within the game in exchange for the illegitimate item or if the item involved in the transaction has since been expended, then complete reversal may be impossible, rather than being only logistically difficult. When reversal is difficult or impossible, game companies may reasonably be expected to save operating costs by not reversing the transactions or removing the illegitimate item from the in-game economy, despite having refunded the parent. This has been documented to be the case in the PRC when refunds were approved in the past at the discretion of Apple in relation to iPhone games. ${ }^{19}$ However, game companies and their players suffer the consequences that the inflation of the designed in-game economy causes.

The game companies' inaction (which, in some cases, is due to an operational inability to act) has been identified and abused by fraudsters. ${ }^{20}$ Tencent, the largest video game company in the world, has reported that its customer support records more than 20 instances of attempted fraud by adults falsely claiming that certain purchases were made by minors to request refund in the PRC every day. ${ }^{21}$ There must also be an additional number of undetected frauds. Further, in relation to

\footnotetext{
19 陈炜 [Wei Chen], 把诚意当生意的苹果退款团有多悬 [How risky are the Apple Store refund groups who abuse good faith for commercial gain], 今日女报 [WOMEN TODAY WEEKLY], March 28, 2019, 6-7, http://jrnb.fengone.com/new / Html/ 2019-03-28/17121.html (last visited May 24, 2020) [https: / / web.archive.org/web / 20200524210034/http: / jrnb.fengone.com/new / Html/2019-0328/17121.html]; http:/ /jrnb.fengone.com/new / Html/2019-03-28/17122.html (last visited May 24, 2020) [https:/ / web.archive.org/web/20200524210041/http:/ /jrnb.fengone.com/new/Html/201903-28/17122.html].

${ }^{20} I d$.

21 若风 [Ruo Feng], supra note 15.
} 
randomised virtual items, such as loot boxes, a child and their parent can potentially work together to renege on a legitimate transaction, if they determine the randomisation results to be unsatisfactory (e.g., they did not receive the rarer and more valuable items they were hoping to obtain), by pretending that the transaction was unauthorised and relying on the Guiding Opinion. Indeed, fraudsters may even refer to this Guiding Opinion as a 'licence' to justify their abusive demand of refunds from game companies when pretending to be parents claiming that these purchases were made without authorisation by minors under eight.

In light of past and potential abuse, game companies operating in the PRC should still be expected to continue to operate their existing, stringent refund approval systems that rely on evidence presented by the parent to determine if the purchase was truly made by a minor without authorisation from their guardian. ${ }^{22}$ Apple App Store's relevant system has been reported to prohibit users from relying on the 'unauthorised minor purchase' excuse to request refund after a certain number of claims by the same account relying on this same reason. ${ }^{23}$ Established game companies in the PRC have already developed customer support systems that are capable of approving refunds when parents legitimately claim with evidence that their child made an unauthorised purchase, whilst at the same time identify and prevent fraud. This Guiding Opinion is unlikely to change these systems in any substantive way. However, in relation to more unscrupulous companies who did not previously consider and offer refunds on a discretionary basis, this Guiding Opinion will now force them to proactively adopt such systems or face litigation.

\section{Acknowledgement}

The Author would like to thank Dr Zhiyu Li for her assistance with clarifying a point of PRC law and Laura L. Henderson for her editorial assistance.

${ }^{22}$ See 陈 [Chen], supra note 19; 若 [Ruo], supra note 15.

23 陈 [Chen], supra note 19. 